\title{
Theoretical and practical aspects of the synthesis of optimal systems of energy complex enterprises for preparation and processing of hydrocarbons
}

\author{
Igor Dolotovskii ${ }^{1, *}$, and Evgeniy Larin ${ }^{1}$ \\ ${ }^{1}$ Yuri Gagarin State Technical University of Saratov, 410054 Saratov, Russia
}

\begin{abstract}
We have developed a technique for structural-parametric synthesis of optimal energy complex enterprises for preparation and processing of hydrocarbons, which employs the decomposition-search principle to create technological and constructive solutions; it is also based on mathematical apparatus of generalized quantitative quality evaluation. Developed the structure and composition of the equipment of the energy complex with the system of electric-, warmly- and water supply. The complex is integrated energy-technological systems, and provide maximum utilization of recycled energy resources and waste. The developed information-program software allows performing an evaluation of the a multi-criterion of the efficiency of systems of energy complex.
\end{abstract}

\section{Introduction}

Energy complex (EC) enterprises preparation and processing of hydrocarbons (EPPHC) includes several systems (fuel, heat and electricity, water supply and cold supply, etc.), forming together with technological systems (TS) a complex set of manufacturing equipment. Machines of EC and TS are consumers and generators of various energy resources (ER) derived from external or own sources, and interconnected with production cycle by material and energy flows. Development and improvement of such complicated structured object, taking into account all factors is possible only on the basis of the system of evidence-based methodology and its software, allowing the synthesis and design of EC with any topology TS at every stage of their life cycle. In the present study we offer methodological position of structural-parametric synthesis - the development of the methodology of system studies in the energy and chemical-technological enterprises [1-3], and examples of solutions of the structure of systems and design hardware EC [4].

\section{Problem statement}

For the synthesis of the EC, optimal in the whole space of changing factors, created the mathematical apparatus of universal quantification of the quality of its functioning within the EPPHC. Need to create a mathematical models of system that include a description of the interrelated processes of generation and consumption of ER, water consumption and water disposal, heat-technological and chemical-technological processes of preparation and processing of raw hydrocarbon. Need to take into account the dynamic parameters of investigated object and hierarchical sets of private indicators and criteria of varying degrees of significance.

The basis of the developed method is decompositionsearch principle of synthesis of energy-technology systems [5], which provides the solution of problems of two hierarchy levels: the first is formed of the technological structure of EC, on the second - it's hardware design and design of information and software.

\section{Theory}

\subsection{Synthesis of technological solutions}

At the stage of conceptual modeling of synthesis technology solutions from many possible principles $\Pi$ $(\pi \in \Pi)$ chosen: $\pi_{1}-$ maximum insularity with the use of its own of recyclable energy resources (RER), combustible waste and wastewater; $\pi_{2}-$ ecological safety; $\pi_{3}$ - reliability of energy supply throughout the life cycle period.

The task of synthesis of technological solutions illustrates a generalized block diagram of EC (Fig. 1). In scheme realized principles $\Pi$, as well multi-functional systems of energy complex and its integration with the systems: technology processing, water supply and wastewater. Electric and thermal energy is generated in own source through the maximum utilization of secondary energy resources - in a combined steam turbine and gas turbine plant (STP and GTP). Process

\footnotetext{
Corresponding author: dolotowsky@mail.ru
} 
heat consumer may 2 include evaporator's absorbents drying and gas purification units, boilers distillation columns, heaters process flows, and other hightemperature equipment.

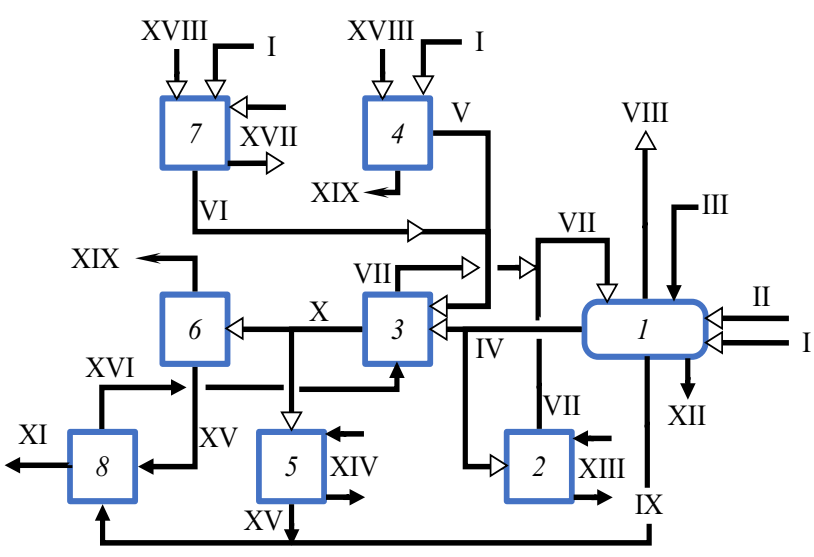

Fig. 1. Scheme of EC with a source of heat-, electric energy, and water supply. The figure: $1-8$ is the plant: 1 is the combustible waste and wastewater utilization; 2,5 is the technological heat-consumer; 3 is the steam generation; 4, 6 is the GTP and STP; 7 is the compressing gas; 8 is the water treatment; I - XIX is the technological and energy flows: I, II is the gas fuel and recyclable; III is the industrial wastewater; IV, V, VI is the high-temperature flue gas; VII, VIII is the gases in the drying and gas dehumidified; IX is the water in the treatment system; X - steam; XI -water system for household consumption; XII is the dry waste; XIII, XIV is the flow technology; $\mathrm{XV}$ is the condensed water; $\mathrm{XVI}$ is the demineralized water; XVII is the gas to compress; XVIII is the air; XIX is the electrical energy.

For auxiliary units of the technological system, for example, for hydrocarbon storage, flue gases neutralizing wastes and gas installation 1 can be used by the consumer 2 in boilers for heating high-temperature intermediate heat carrier used for heating tanks in the winter. Consumer technology 5 depending on technological topology can be formed from equipment: boilers columns; absorption or compression chillers (compressors driven by steam turbines or rotary steam engines); equipment heating and hot water systems and other heat consumers.

\subsection{Synthesis of structurally-hardware design}

Development of options for hardware design with optimized of constructive and operational parameters was carried out by the algorithm is implemented as a network model (Fig. 2).

Developed solutions of options of EC [5] assessed on energy, techno-economic and the additive-multiplicative factors: exergy efficiency; factors rationalization of fuel and energy and water balance; the integral effect, payback period, the complex criteria $[4,6,7]$. The last group of criteria has the form of functional

$$
\Phi(\mathbf{u}(x))=\sum_{i=1}^{k} \gamma_{i} u_{i}(x)+\sum_{i=1}^{k} \sum_{j=1}^{k} \gamma_{i j} u_{i}(x) u_{j}(x)+\ldots,
$$

where $\mathbf{u}(x)$ is the vector of indicators of efficiency options for EC $x ; \gamma_{i}$ is the indicator of importance; $\gamma_{i j}$ is the coefficient taking into account the linkages indicators.

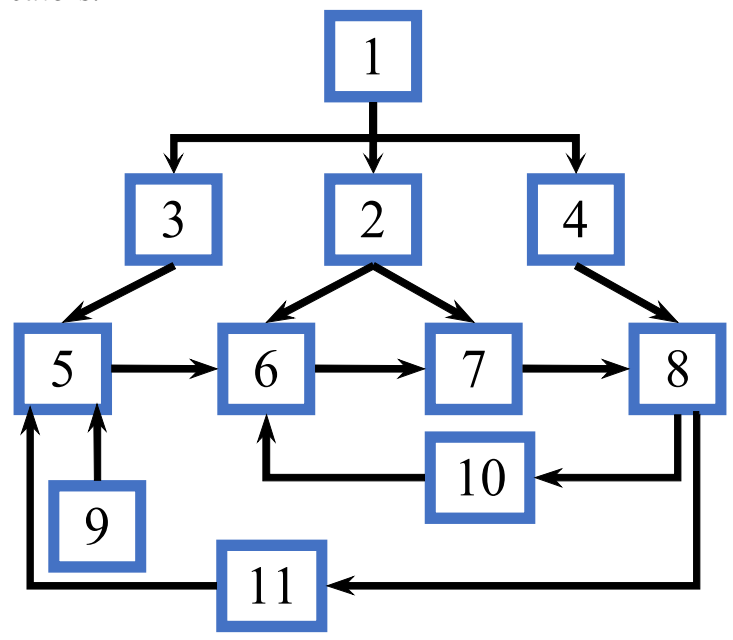

Fig. 2. Scheme of the synthesis of the optimal EC.

The figure: 1 is the terms of reference; 2 is the independent input data; 3 is the demand for the operation; 4 is the effectiveness criteria; 5 is the formation structure; 6 is the formation model; 7 is the description of the model; 9 is the database; 10 is the optimization parameters; 11 is the change of structure.

The sum (1) contains components $\gamma_{i j} u_{i}(x) u_{j}(x)$ that enable to assess the mutual influence of the partial indicators of the effectiveness on an integrated criterion. The functional $\Phi(\mathbf{u}(x))$ shows that the impact of the private indicator $u_{i}$ (e.g., Integral effect) on the evaluation of alternative energy of the complex depends not only on its value for the variant $u_{i}(x)$, but also from the values $u_{j}(x)$ of indicator $u_{j}$ for this variant (e.g., a of fuel economy or water resources).

The cumulative index of efficiency (CIE) of EC of multi-purpose EPPHCs formed from the partial criteria of technological [7], energetic, economic and of ecological efficiency. The criteria are grouped into two sets: the criteria of production and economic activities to ensure the profitability and efficiency of the enterprise as an economic asset (effectiveness) $r_{p}(t)$; efficiency criteria $\lambda_{l}(t)$ which characterize the degree of realization of the basic principles $\pi_{1 \ldots 3} \in \Pi$ during the accounting period.

Elements are normalized relative to the «basic» version of the object: a draft version of the operating enterprise; object with a similar factor of structural complexities and of topologies technology (with weighted average values of indicators).

Set of effectiveness elements $r_{p}(t)$ includes 6 indicators $(p=1 \ldots 6): R(t)$ is the value of goods sold; $C_{1}(t) \ldots C_{5}(t)$ is the operational costs of the main production (costs of raw and auxiliary materials, energy and water from an external source; maintenance, repair and depreciation, fees for the disposal of waste, industrial emissions and waste water).

The second set $\lambda_{l}(t)$ containing the elements of effectiveness include 5 vector criteria (combining 17 
indicators) and of productivity to hydrocarbon raw materials $V_{H R M}$. In total, this set of 6 indicators, $l=p=6$.

Vectors of efficiency criteria $U_{1}(t) \ldots U_{5}(t)$ are formed from of the following characteristics and metrics calculated for time $t$ :

- efficiency of use of raw materials and processing products

$$
\begin{aligned}
U_{1}= & 0,417 \bar{G}_{R}+0,263 \gamma_{\mathrm{c}}+0,160 \beta_{x}+ \\
& +0,097 \bar{\Delta}_{R C}+0,062 \eta_{\mathrm{EC}},
\end{aligned}
$$

where $\bar{G}_{R}$ is the change in the volumes of products sold (relative to the «base» variant); $\gamma_{c}, \beta_{x}$ is the coefficients of the utilization of raw materials and production sold of by-products; $\bar{\Delta}_{R C}$ is the difference between the cost of products sold and raw material costs; $\eta_{\mathrm{EC}}$ is the rationalization factor energy costs;

- potential of increasing use of ER, water and waste recycling

$$
\begin{aligned}
U_{2}= & 0,381 \bar{E}+0,252 \eta_{0}+0,16 \eta_{\mathrm{FEB}}+ \\
& +0,101 \eta_{W}+0,064 \eta_{L}+0,043 \bar{P}_{E},
\end{aligned}
$$

where $\bar{E}$ is the useful used energy of external fuelenergy resources; $\eta_{0}$ is the coefficient of relative energy savings; $\eta_{\mathrm{FEB}}$ is the rationalization factor of the fuelenergy balance; $\eta_{W}$ and $\eta_{L}$ are factor of rational water consumption from an external source and of water disposal; $P_{\Sigma}$ is the technically realizable potential by the use of all types of resources;

- use of ERs and economy fuel in system

$$
\begin{aligned}
& U_{3}=0,417 \eta_{\Sigma}+0,263 \eta_{F Q}+0,16 \eta_{u}^{\mathrm{RER}}+ \\
& +0,097 \eta_{e x}+0,062 \overline{\Delta F}
\end{aligned}
$$

where $\eta_{\Sigma}$ is the total of energy efficiency; $\eta_{F Q}$ is the utilization factor of heat fuel for heat generation; $\eta_{u}^{\text {RER }}$ is the utilization factor of RERs; $\eta_{e x}$ is the exergy efficiency; $\overline{\Delta F}$ is the system fuel economy;

- costs for assurance the reliability of ERs supply and water supply and for of reservation

$$
U_{4}=0,5 \bar{C}_{H S}+0,5 \bar{K}_{1}(\Omega, Z),
$$

where $\bar{C}_{H S}$ is the costs for assurance the reliability of ERs supply and water supply; $\bar{K}_{1}(\Omega, Z)$ is the capital cost to reserve of technology equipment, as a function of process $(\Omega)$ and design $(Z)$ factors;

- compensation damage environmental

$$
U_{5}=0,540 \eta_{W}+0,297 \eta_{L}+0,163 \bar{K}_{2}(\Omega, Z),
$$

where $\bar{K}_{2}(\Omega, Z)$ is the capital cost to reserve of equipment for waste disposal systems and drains.
The coefficients in (2) - (6) are the rank coefficients of the partial efficiency criteria calculated by the hierarchy analysis method [8].

When deciding about the priority of sets we adopted the concept of equivalency, since when the structuralparametric optimization of EC and the implementation of the principles of efficiency should be retained (or be increased) of profitability of the enterprise.

The formula CIE merges the generated values of fractional deviation of each indicator with consideration of the coefficients of potential.

$$
\begin{gathered}
C I E=4,117 \frac{R(t) / R^{0}(t)}{\sum_{p=1}^{6} r_{p}(t) / r_{p}^{0}(t)}- \\
-34,72 \sum_{i=1}^{5} \frac{C_{i}(t) / C_{i}^{0}(t)}{\sum_{p=1}^{6} r_{p}(t) / r_{p}^{0}(t)}+ \\
+25,0 \frac{\sum_{i=1}^{3} U_{i}(t) / U_{i}^{0}(t)}{\sum_{l=1}^{6} \lambda_{l}(t) / \lambda_{l}^{0}(t)}- \\
-16,67 \frac{\sum_{i=4}^{5} U_{i}(t) / U_{i}^{0}(t)}{\sum_{l=1}^{6} \lambda_{l}(t) / \lambda_{l}^{0}(t)}+ \\
+8,33 \frac{V_{H R M}(t) / V_{H R M}^{0}(t)}{\sum_{l=1}^{6} \lambda_{l}(t) / \lambda_{l}^{0}(t)}
\end{gathered}
$$

where the subscript «0» denotes indicators of the basic variant.

The coefficients of potentials (7) generated from the three factors, allowing to establish the direction of potential $(+1$ or -1$)$, to ensure a balance between effectiveness $r_{p}(t)$ and efficiency $\lambda_{l}(t)$, to determine the importance (weight) of each indicator.

The balance factor of the coefficients of the potentials is $1 / 6$, if the indicator is the only one in the set $r_{p}(t)$ or $\lambda_{l}(t)$, and is multiplied by the corresponding number of repeated calculation for each set. Thus, the coefficient of potential of the first indicator (7) is defined as follows:

$$
4,117=[+1] \times\left[\frac{1}{6} \times 0,5\right] \times\left[\frac{\sum_{p=1}^{6} R_{p}(t)}{\sum_{p=1}^{6} \sum_{l=1}^{6} R_{p l}(t)}\right] \times 100 .
$$

It should be emphasized that in the general case, all indicators have a weighting factor as part of the coefficients of the potentials. However, for performance measurement of the set $\lambda_{l}(t)$ it is equal to 1 .

The values of other coefficients for CIE obtained similarly the (8). The higher the CIE, the more effective option ECs EPPHCs. 


\subsection{Information and software synthesis systems}

The information-analytical system (IAS) [9] consists of software and computational and information-methodical units and modules (Fig. 3).

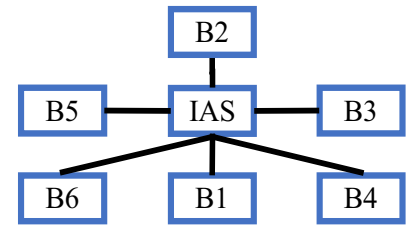

Fig. 3. Scheme IAS. The figure: $\mathrm{B} 1-\mathrm{B} 6$ - blocs: $\mathrm{B} 1$ is the structured data of equipment; B2 is the modeling program; B3 is the methodical documentation; B4 is the normative documents; B5 is the experimental information; B6 is the instructions to the user.

With the help of the IAS implemented numerical method of a computer experiments with mathematical models that describe the behavior of individual components and the whole EC for a specified period or the configured period of time.

Information in single blocks of IAS is structured by the elements of EC and TS EPPHC, which in turn commute to each other via entry and exit signals. Each output signal $\left(Y_{s j}^{n}\right)$ from one or component is input to the other component of the system $\left(X_{s j}^{k}\right)$, or included in the overall system output signal (the subscripts refer to the subsystems, the top - to complex signals). Generally, $k \neq n ; k$ and $n$ are different for each system.

The mathematical scheme by which describes the real processes in the components of block B2 (RF computer programs numbers: 2010615353, 2011616340 , 2011616684, 2012612727, 2012613267, 2012613266, 2012613269, 2014613737, 2014619488, 2014660962, $2014660407,2016610685)$, presented in IAS in the form of aggregate (AG).

At any time the AG can be in one of possible states. The transition of the AG from one state to another is described by a transition operator, which allows you to define by a previous state of AG next state of the AG. The AGs have inputs, which receive inputs from the other AGs, and outputs on which are generated output signals. In addition, the AGs have additional inputs, which receive the control signals. The outputs signals are generated by operator of output from the input and the control signals, because of its interaction with the transition operator. The values of the operators of transition and exit are defined at the approximation of the execution of AGs of the functional action of the real system.

\section{The results of the experiments}

Developed theoretical principles of synthesis of optimal systems ECs EPPHCs implemented in the project of modernization of heat- and electric power systems for the enterprise of processing sour gas and gas-condensate.
With the using software of IAS have been conducted numerical experiments with models of ECs different structures, composition equipment and modes of operation.

Variants of EC were assessed both by private criteria of efficiency, and by CIE and fuel economy.

Key performance indicators for the investment project of creation and functioning of the EC with an independent source a electricity-, heat-, water- supple system in the structure of the multidisciplinary EPPHC for different variants of equipment are presented in the table.

Table. Efficiency characteristics of EC EPPHC variants.

\begin{tabular}{|c|c|c|c|}
\hline \multirow{6}{*}{ Index } & \multicolumn{3}{|c|}{ Gas turbine plants (GTP) } \\
\hline & $\begin{array}{c}3 \times \text { GT8C2 } \\
\text { ALSTOM }\end{array}$ & $\begin{array}{c}2 \times \mathrm{V}- \\
64.3 \mathrm{~A} \\
\text { SIEMENS }\end{array}$ & $\begin{array}{c}4 \times G T X-100 \\
\text { ALSTOM }\end{array}$ \\
\hline & \multicolumn{3}{|c|}{ Heat-recovery steam generators $(\mathrm{KU})$} \\
\hline & $3 \times K U-93$ & $\begin{array}{c}2 \times K U- \\
120\end{array}$ & $4 \times K U-60$ \\
\hline & \multicolumn{3}{|c|}{ Steam turbines } \\
\hline & $\begin{array}{c}3 \times K-6-2.4 \\
\text { KTZ }\end{array}$ & $\begin{array}{c}2 \times K-6-2.4 \\
\text { KTZ }\end{array}$ & $\begin{array}{c}2 \times K-6-2.4 \\
\text { KTZ }\end{array}$ \\
\hline $\begin{array}{c}\text { Power (MW): } \\
\text { electrical } \\
\text { thermal } \\
\end{array}$ & $\begin{array}{l}192 \\
163 \\
\end{array}$ & $\begin{array}{l}158 \\
163 \\
\end{array}$ & $\begin{array}{l}190 \\
163 \\
\end{array}$ \\
\hline $\begin{array}{l}\text { Fuel rate to } \\
\text { generate power: } \\
\text { electrical (tons of } \\
\text { reference } \\
\text { fuel/MW·h) } \\
\text { thermal (tons of } \\
\text { reference fuel/GJ) }\end{array}$ & $\begin{array}{l}0.161 \\
0.045\end{array}$ & $\begin{array}{l}0.158 \\
0.042\end{array}$ & $\begin{array}{l}0.164 \\
0.046\end{array}$ \\
\hline $\begin{array}{l}\text { Rationalization } \\
\text { factor: } \\
\text { of energy } \\
\text { consumption, } \eta_{\text {FEB }} \\
\text { of water } \\
\text { consumption, } \eta_{\mathrm{W}} \\
\text { of water disposal, } \\
\eta_{\mathrm{L}}\end{array}$ & $\begin{array}{l}0.255 \\
0.914 \\
0.974\end{array}$ & $\begin{array}{l}0.316 \\
0,912 \\
0,974\end{array}$ & $\begin{array}{l}0.217 \\
0.912 \\
0.974\end{array}$ \\
\hline Integral effect, $\%^{a}$ & 137.18 & 117.47 & 135.49 \\
\hline $\begin{array}{l}\text { Annual fuel } \\
\text { savings, } 10^{3} \text { tons } \\
\text { equivalent fuel; } \\
\text { in electricity } \\
\text { generation: } \\
\text { is the GTP and } \\
\text { STP condensed } \\
\text { type } \\
\text { is the separate } \\
\text { method with a } \\
\text { weighted average } \\
\text { efficiency } \\
\end{array}$ & 119.7 & 123.2 & 104.1 \\
\hline CIE & 25.3 & 24.1 & 22.5 \\
\hline
\end{tabular}

\section{The discussion of the results}

Developed technological solutions for the structure of the EC have a number of advantages: 
- efficiencies of energy at the expense of utilization useful heat from the flue gases in heat recovery boilers to generate steam;

- of use as a fuel gas liquid and gas wastes in the neutralizer waste; this reduces the specific fuel consumption for the joint production (cogeneration) of electricity and heat, cold supply and water supply;

- increase of ecological safety of EPPHCs due to the thermal neutralization of industrial and drainage effluents, the water of separating and water flushing equipment;

- reduced costs for water supply through the use condensate of steam as the working substance in steam-power plant and in systems water for the system of economic-drinking water supply;

- in hardware design of EC its installations as much as possible integrated with TS, so not in need of replacement by decommissioning, or in in the conservation and used at all stages of the life cycle EPPHC, from beginning construction of the facility before its decommissioning.

Evaluation of the effectiveness of technical solutions made out on the basis of a complex of energy-economicand-environmental indicators.

A balanced approach of technique choice of CIE allows you to exclude bias or subjectivity in the synthesis of the optimal EC, which is especially important in the processes of hydrocarbon processing. Use single criteria for these enterprises can lead to incorrect conclusions, to the detriment of such components of efficiency as the reliability of ERs, ecological safety, system energy efficiencies and other factors.

The developed software has allowed to define, on the basis of simulation, performance indicators EPPHCs with different versions of ECs. For example, for shown in table three of variants heat-, electricity-, and watersupply systems, is the most effective first variant, is characterized by a maximum value of CIE and the integral effect in comparison with a variant of EC of the acting EPPHC.

\section{Conclusions}

A developed method of structural-parametric synthesis of optimal variant of an independent source of power supply for energy complex enterprises for preparation and processing of hydrocarbons.

Presents the factors that determine the technoeconomic, energy, ecology effectiveness and efficiency of enterprises of preparation and processing of hydrocarbons. Developed alternative structure energy complex with a source of electrical and thermal energy and water supply, integrated with the technological system and ensuring maximum utilization of recovery energy resources and waste disposal.

With using the information and software made evaluation of the efficiency of alternative variants of the system of electricity-, heat-, water supply for multidisciplinary enterprises on processing of gas and gas condensate.

This work was supported by the Ministry of Education and Science of the Russian Federation, within the framework of a state assignment.

\section{References}

1. G.M. Ostrovsky, T.A. Berezinsky, A.R. Belyaev, Algorithms for optimization of chemical processes (Chemistry, Moscow, 1978)

2. V.V. Kafarov, V.P. Meshalkin, Analysis and synthesis of chemical-technological systems (Chemistry, Moscow, 1991)

3. D.A. Marca, C.L. McGowan, SADT: Structured Analysis and Design Techniques (McGraw Hill Software Engineering Series, 1987)

4. I.V. Dolotovskii, E.A. Larin, N.V. Dolotovskaya, Design and optimization of plants and systems and energy complex of the industrial enterprises (Amirit, Saratov, 2015)

5. I.V. Dolotovskii, A power, heat, and water supply installation for hydrocarbon raw material production, transportation, and processing enterprises (RU Patent 118360, 20, 2012)

6. N. Korovkin, M. Odintsov, N. Belyaev, O. Frolov, H. Masashi, IEEE Conference Publications, 12-14 (2014)

7. A. Tonchev, C. Tonchev, Oil \& Gas Journal, 10 (2005)

8. T. Saaty, L. Thomas, Multicriteria Decision Making - The Analytic Hierarchy Process (RWS Publications, Pittsburg, 1992)

9. I.V. Dolotovskij, E.A. Larin, N.V. Dolotovskaya, The information-analytical system of standardization and optimization of production and consumption of fuel and energy resources in the enterprise (RU Patent 2465639, 30, 2012) 